\title{
Challenges of developing sports medicine in the Netherlands ... work in progress!
}

\author{
Fred Hartgens $\odot$, 1,2 Frank J G Backx ${ }^{3}$
}

Sports medicine was finally recognised as a full medical specialty in the Netherlands, comparable with the position of orthopaedic surgeons and cardiologists, on 1 July 2014; nearly 50 years after the Dutch Association of Sports Medicine (VSG) was founded by a handful of enthusiastic pioneers on 8 May 1965. From these humble beginnings, sports medicine gradually gathered momentum and a 4-year full-time training, similar to that seen in other medical disciplines, was introduced in 1991. These pioneers were regarded as 'upstarts' in the Dutch healthcare system, but by combining their efforts from the start, and by focusing on the single goal to make sports medicine a new medical specialty, they were able to create new opportunities (and challenges) for young doctors with an interest in sport.

\section{DUTCH SPORTS MEDICINE SCIENCE AGENDA}

Sports medicine includes prevention, diagnostics, treatment and rehabilitation, with a view to maintain or improve performance at every level. As with every medical specialty, there is a constant need to extend our knowledge, and expertise, and to make the latest advances more accessible to athletes, players, parents and coaches. To achieve this the VSG, in close collaboration with the majority of the 150 sports medicine specialists, developed a science agenda to address the challenges that were anticipated in the upcoming years. Among the main topics identified were overuse injuries (with special reference to tendinopathies), exercise is medicine and exercise diagnostics. These topics will all be addressed at the annual scientific meeting of the VSG, taking place on 28 and 29 November 2019 in the picturesque

${ }^{1}$ Epidemiology and Surgery, CAPHRI Research School, Maastricht University Medical Center, Maastricht, The Netherlands

${ }^{2}$ Sports Medicine Center Maastricht*Parkstad, Maastricht, The Netherlands

${ }^{3}$ Rehabilitation and Sports Medicine, University Medical Center Utrecht, Utrecht, The Netherlands

Correspondence to Dr Fred Hartgens, Epidemiology، Maastricht University Medical Center, Maastricht 6200 MD, The Netherlands;

f.hartgens@maastrichtuniversity.nl

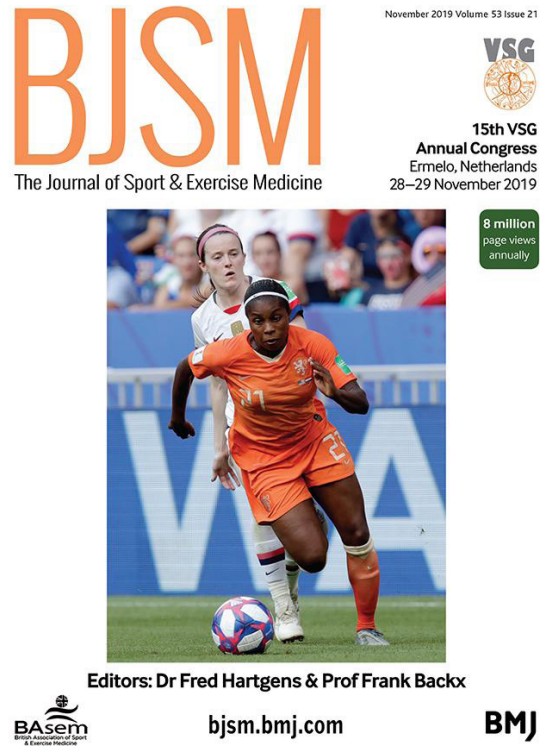

Copyright: Royal Nederlands Football Association

town of Ermelo. The programme closely follows the VSG science agenda, with key note lectures on Exercise in unintended sedentary people (Professor Wagenmakers, UK), Sports participation in athletes with cardiomyopathies (Professor Corrado, ITA), Tendinopathies (Professor Zwerver, NED) and the Rehabilitation of ankle injuries (Professor Delahunt, IRE).

It will therefore come as no surprise that this issue of the BJSM incorporates some of the major topics of the VSG science agenda, as well as articles on medical issues on football, the most popular sport worldwide.

\section{FOOTBALL: PREVENTION, TREATMENT, REHAB}

The incidence rates of injuries in team sports that involve contact are relatively high, especially in women's football is growing rapidly. ACL rupture is one of the most severe injuries in sport and results in long-term rehabilitation before any return to sports is possible. Montalvo et al (See page 1333) performed a systematic review to answer the important question-which players are more at risk of this serious injury. They reported that females have an increased incidence of ACL injury, compared with male football players, and that this is independent of the level of play. They found no difference in the relative risk.

For a long time, little attention has been paid to head injuries and sport-related concussion in football, particularly when compared with rugby and American football. In recent years, awareness about the impact of heading the ball in football has grown, and this is well described in the paper of Putukian et al (See page 1332). The authors have also included practical recommendations for healthcare providers based on state-of-the-art evidence.

In the Netherlands, several injury registration systems and randomised controlled trials involving injury prevention have been developed. Measures like ankle bracing, stabilising exercises for the ankles and the Nordic hamstring curl are proven to be effective. ${ }^{12}$ The article by Van Dyk et al (See page 1362) underlines the necessity of performing the Nordic hamstrings exercises, knowing that a hamstrings injury is the most prevalent muscle injury in football players. Unfortunately, compliance with these effective measures remains the major obstacle towards accomplishing injury reduction in the sport setting. ${ }^{2}$

In their contribution 'Injury prevention training in football: Let's bring it to the real world,' Nassis et al (See page 1328) make a plea for incorporating an injury prevention programme throughout the entire year and emphasise the importance of that programme during off-season. Despite the overwhelming evidence for effective injury prevention programmes, Buchheit et al (See page 1327) cite a survey that showed $83 \%$ of UEFA clubs have not yet adopted an evidence-based prevention programme. In their paper they illustrate the complexity of incorporating these programmes at the elite level; a major challenge to everyone involved.

\section{EXERCISE IS MEDICINE IN HEALTHY} AND CHRONICALLY ILL PEOPLE

Exercise is medicine is a well-accepted concept worldwide. In many countries, physical activity guidelines have been developed and are used by healthcare professionals. ${ }^{3}$ The principle that lifelong regular physical activity is beneficial to health is well recognised but integrating this with the degenerative processes associated with ageing remains a challenge. Two interesting infographics by Oja et al (See page 1379) and Stamatakis et al (See page 1381) address the role of frequency, intensity, type and duration of walking on cardiovascular disease (CVD) risk factors and the relationship between self-rated walking pace and CVD and cancer mortality. 
In patients suffering from chronic conditions, including diabetes, obesity, and many others, an active lifestyle, regular physical activity and exercise training have a beneficial influence on the disease, as well as improving the quality of life and reducing mortality. Steell et al (See page 1371)

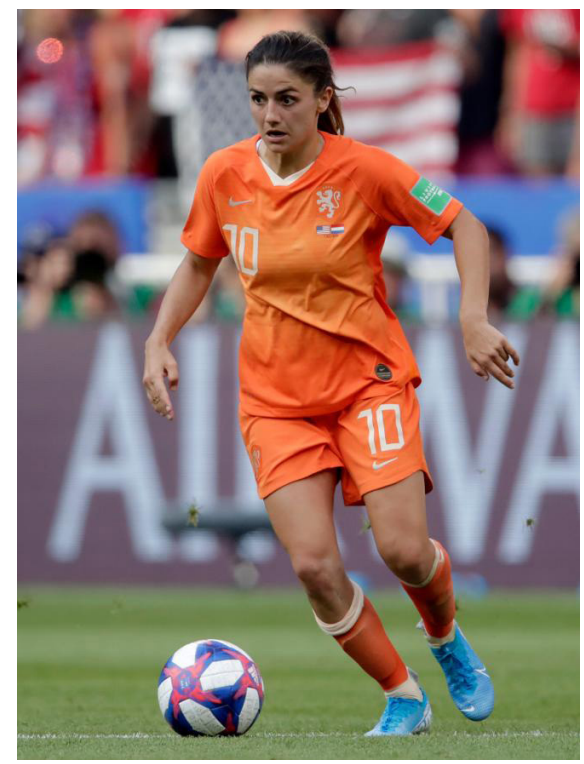

Copyright: Royal Nederlands Football Association provide data from the UK Biobank cohort study underpinning the protective role of a high cardiorespiratory fitness in patients suffering from cancer, cardiovascular and respiratory diseases. In a systematic review and meta-analysis, Mitchell et al (See page 1341) describe the importance of aerobic exercise intensity on cardiorespiratory fitness in patients undergoing cardiac rehab.

\section{WHAT ABOUT TENDONS?}

Clinicians are keen to identify those risk factors that cause or maintain injuries, eventually leading on to chronic overuse. Looking at risk factors in Achilles tendinopathy, a Dutch research group found that the use of quinolones, alcohol consumption and reduced plantar flexion strength of the foot were the only modifiable risk factors (See page 1352). Finally, the role of isometric exercises for pain relief in tendinopathies is well described in a short communication by Silbernagel et al (See page 1330) that provides a practical take-home message for the management of tendinopathies.

We look forward to meeting you in Ermelo on 28-29 November!

\section{Collaborators Frank Backx.}

Funding The authors have not declared a specific grant for this research from any funding agency in the public, commercial or not-for-profit sectors.
Competing interests None declared.

Patient consent for publication Not required.

Provenance and peer review Commissioned; internally peer reviewed.

Author note Frank Backx is currently the President of the VSG. Fred Hartgens is a board member of the VSG, with portfolio "Science and Innovation".

(c) Author(s) (or their employer(s)) 2019. No commercial re-use. See rights and permissions. Published by BMJ.

\section{D) Check for updates}

To cite Hartgens F, Backx FJG. Br J Sports Med 2019:53:1325-1326.

Accepted 30 August 2019

Br J Sports Med 2019;53:1325-1326.

doi:10.1136/bjsports-2019-101476

\section{ORCID iD}

Fred Hartgens http://orcid.org/0000-0002-1466-4954

\section{REFERENCES}

1 Janssen KW, van Mechelen W, Verhagen EALM. Bracing superior to neuromuscular training for the prevention of selfreported recurrent ankle sprains: a three-arm randomised controlled trial. Br J Sports Med 2014;48:1235-9.

2 Van der Horst N, Van de Hoef S, Van Otterloo P, et al. Effective but not adopted. understanding why evidencebased hamstring injury prevention is not adopted in amateur football. Clin I Sport Med 2018. [Epub ahead of print].

3 Weggemans RM, Backx FJG, Borghouts L, et al. Committee Dutch physical activity guidelines 2017. The 2017 Dutch physical activity guidelines. Int I Behav Nutr Phys Act 2018;25. 